\title{
Necesidad de un cambio de la Gerencia de hoy
}

No hay dudas que el entorno de hoy está en permanente cambio. Dejó, hace rato de ser estable, seguro, predecible. Tanto así, que permitió a Max Weber hacer una teoría Burocrática que durante decenas de años fue el libro de mano de la gerencia tradicional, casi garantizando el éxito de quienes tenían presente los principios administrativos que había que aprenderlos como los diez mandamientos de la tabla de Moisés.

Por otra parte, los capitanes de las organizaciones, fueran directivos, gerentes medios o supervisores eran investidos por la autoridad, que daba el mismo cargo, para gobernar de manera legal las relaciones de poder entre ellos y los subordinados. Así, que había una simbiosis entre el aparato administrativo, la autoridad conferida y el carisma de quien ejercía el poder. Claro, tampoco podía faltar la experiencia que era un aditivo conveniente para garantizar que las órdenes tuvieran fiel cumplimiento y garantizar el éxito.

Por supuesto, la realidad de hoy tiene variantes significativas que no permiten a los gerentes tomar esos principios al pie de la letra para garantizar los objetivos declarados por las empresas que representan. Se hace difícil, por ejemplo, cumplir la máxima de la unidad de mando. Muy difícil, cuando las decisiones deben ser tomadas de manera rápida porque el tiempo hoy es más cortó y apremia. Por otra parte, no se tienen cuadrillas de trabajadores. Hoy se conforman equipos de trabajos. Los cuales, tienen información y conocimientos generalmente superiores a los propios directivos. Otro elemento adicional o complementario, mejor decirlo, es la mayor resistencia que tienen los trabajadores al poder normado. Ni la coerción ni el miedo son garantía de que las cosas irán bien. Ni siquiera de que las cosas se harán. Esas relaciones estables han dicho adiós a la gerencia actual. Así, que nuevos elementos están presentes en la actual realidad empresarial que incluyen distintos estados e incluso procesos, a veces hasta incongruentes y contrarios. 
Es visible en estos momentos, nóminas con trabajadores que pertenecen a diversas culturas, una gran complejidad en las decisiones internas que deben tomar los gerentes de la misma. En cuanto a quienes conducen, de acuerdo a como lo señala Etkin (2009) las imperfecciones organizacionales hay que resolverlas con nuevos sistemas de información y control integrados con procesos de aprendizaje, con negociación y mejor adaptación al medio.

Ahora bien, cabe preguntarse: ¿Cómo estamos respondiendo a la formación de esas nuevas cualidades gerenciales? ¿Por qué permanecen los mismos temas en la escuelas de gerencia?. Debe tenerse presente que la formación gerencial no puede estar basada en solo planificaciones con objetivos, políticas, estructura y procedimientos como si viviéramos en un entorno estático, estable, tradicional.

Contrario a lo anterior, en las organizaciones actuales enmarcadas en la complejidad las actividades hay que llevarlas a cabo dentro y fuera de las normas, decisiones nacidas de pautas informales. Además, hay que tener presente que la influencia no viene de la autoridad. En fin, hay realidades distintas y con ellas se debe bregar.

Por lo tanto, nuestra invitación desde Gestio et Productio. Revista Electrónica de Ciencias Gerenciales, para estimular investigaciones que nos permitan avizorar los grandes temas que deben estar presentes en un diseño particular de formación gerencial. Como camino de inicio pensamos no pueden faltar los estudios de Geopolítica de la realidad reciente, la Dialéctica como lógica de la acción siempre inacabada, las diferencias culturales.

Se requiere entonces, inicialmente actualizar a quienes impartimos cátedras de gerencia. Desde aquí solo nos atrevemos a asegurar que hoy la gerencia no se enseña. Pero sí hay que aprenderla.

\author{
Dr. Mario Antonio Ramírez-Pérez \\ mario.ramirez@grupocieg.org \\ Centro de Investigaciones y Estudios Gerenciales (CIEG), Yaracuy \\ Venezuela \\ https://orcid.org/0000-0002-7145-5577
}

